\title{
THE MATERIAL AND THE PSYCHOLOGICAL: AN ANALYSIS OF THE CLAUSE STRUCTURE OF TAGALOG USING COGNITIVE GRAMMAR
}

\author{
Jem R. Javier \\ Department of Linguistics \\ College of Social Sciences and Philosophy \\ University of the Philippines Diliman \\ (jemroquejavier@gmail.com)
}

\begin{abstract}
For this paper, the researcher attempts to describe the clause structure of Tagalog using Cognitive Grammar (CG). Abiding by the said framework, sentences are regarded as grammatical constructions that represent different event schemas, which are then categorised into situations in: (1) the material world, or how the structured world exists, changes, or undergoes processes; and (2) the psychological world, or the internal world of human sensation, emotion, perception and thought. Analysing the semantic grammar of Tagalog, that is, looking at linguistic utterances as motivated by the meaning that the speaker wants to express, this study aims to provide new insights with regards to the characteristics of the components of grammar as a reflection of cognition.
\end{abstract}

Keywords: Tagalog, Cognitive Grammar, event schema, semantic grammar, cognitive linguistics

\section{Introduction}

The concept of "grammar" that is not limited to morphosyntax, but incorporates the system of meaning assignment, or semantics, is fostered by a relatively new theoretical framework in the scientific study of language, Cognitive Linguistics, which arose during the '70s based on studies on Gestalt, and system of categorisation among humans. According to the cognitive framework, grammar is regarded as a meaningful system in itself; therefore it integrates and cannot be separated from semantics. One of the main ideas being advanced by Cognitive Linguistics is Cognitive Grammar, whose main principle states that a 
grammatically well-formed sentence should not be semantically anomalous; a grammatically sound construction is not separated from it being perceived as acceptable or sensible to the speaker.

Furthermore, one of the main doctrines of Cognitive Grammar (CG) is its high regard on semantics, or meaning assignment. CG perceives semantics as incorporated into syntax; therefore; an utterance is seen as motivated by what needs to be expressed, more than deconstructing the meaning based on the syntactic structure of grammatical constructions; constructions that express what we will now call event schemas.

In this paper, different event schemas in Tagalog, one of the more well known Austronesian languages in the Philippines and the Southeast Asian region (Jubilado, 2008), shall be discussed, with emphasis on the form of sentence that occurs in the expression of a particular event schema. Data that were gathered are all basic sentences, and the predicates used are what can be considered as prototypes of the respective predicates of the event schemas. The resercher gathered and analysed Tagalog constructions that are used in everyday and common discourse. And, since the researcher is also a native Tagalog speaker, introspection $^{1}$ is also used in order to determine the grammaticality and/or acceptability of the constructions that were gathered and analysed.

Studies on the structure of Tagalog are neither scarce nor relatively new; however, analysing its grammatical structure based upon the theoretical framework stated by CG is preliminary ${ }^{2}$. This paper therefore aims to look into the characteristics of Tagalog clause structure through the lens of Cognitve Grammar. In this study the researcher shall not look at the difference of CG to other existing theories ${ }^{3}$, even though the beginnings of the Cognitive Linguistics enterprise to which the said framework belongs resulted from an explicit reaction against the generative tradition of the scientific study of language. Hence, there will be a number of points in this research that carry this implication.

\section{Clause structure as expression of event schema}

An expression is a grammatical construction that is dependent of the conceptual core of a situation (Radden \& Dirven, 2007: 269). Within the conceptual core, the participants are given functions; the semantic role that the participants play in a certain situation is called participant role. The most salient participant roles are AGENT, THEME, and EXPERIENCE. The participant that does an action is called the AGENT. The THEME is the role that is played by the participant that is affected by an action, or that whose participation in a situation is considered passive. This role is also assigned to the subject of a non-verbal sentence. The participant that undergoes emotional, perceptual, or mental experiences is called EXPERIENCER. The roles that are involved in a conceptual core give meaning to the role 
configuration, which are the building blocks of the event schema, or the types of situations that describe a unique configuration of participant roles (Radden \& Dirven, 2007: 339). These event schemas are then expressed through a number of sentence patterns, which may be intransitive, transitive, or ditransitive ${ }^{4}$ (Radden \& Dirven, 2007). The relationship between the event schema and sentence pattern will be shown below.

Event schemas are expressed by grammatical constructions. These grammatical constructions, which are expressed by clauses and sentences, are also called sentence patterns. Each sentence pattern has its own syntactic function and is based on which constituent/s is/are obligatorily expressed. The obligatory ${ }^{5}$ constituents are predicate $(\mathrm{P})$, subject $(\mathrm{S})$, direct or prepositional object $(\mathrm{O})$, and other complements which build up the semantics of the predicate $\left(\mathrm{C}_{\mathrm{P}}\right)$. A number of basic sentence patterns in Tagalog based on this paradigm are shown below:

\section{(1) Non-verbal}

$\begin{array}{ll}\text { Maganda } & \text { ang dalaga. } \\ \text { beautiful } & \text { the maiden } \\ \mathrm{P} & \mathrm{S}\end{array}$

The maiden is beautiful.

(2) Intransitive

Natulog ang binata.

to sleep.PRF the bachelor

$\mathrm{P} S$

The bachelor had slept.

(3) Intransitive predicate-complement

$\begin{array}{lll}\text { Pumunta } & \text { sa Malabon } & \text { ang guro. } \\ \text { to go.PRF } & \text { to Malabon } & \text { the teacher.FOC } \\ \mathrm{P} & \mathrm{CP} & \mathrm{S}\end{array}$

The teacher had gone to Malabon.

(4) Transitive

$\begin{array}{lll}\text { Kumain } & \text { ng saging } & \text { ang unggoy. } \\ \text { to eat.PRF } & \text { a banana } & \text { the monkey.FOC } \\ \mathrm{P} & \mathrm{O} & \mathrm{S}\end{array}$

The monkey had eaten a banana. 
(5) Transitive predicate-complement

$\begin{array}{ccccc}\text { Humiram } & \text { ng aklat } & \text { sa Main Lib ang estudyante. } \\ \text { to borrow.PRF } & \text { a book } & \text { at the Main Lib the student.FOC } \\ \text { P } & \text { O } & C_{P} & S\end{array}$

The student had borrowed a book at the Main Lib.

$\begin{array}{cccc}\begin{array}{c}\text { (b)Nagsibak } \\ \text { to chop.PRF }\end{array} & \begin{array}{c}\text { ng kahoy } \\ \text { (a piece of) wood }\end{array} & \begin{array}{l}\text { sa gubat } \\ \text { at the forest }\end{array} & \begin{array}{c}\text { para sa dalaga } \\ \text { for the maiden }\end{array} \\ \text { P } & \text { O } & C_{P} & C_{P}\end{array}$

ang binata.

the bachelor.FOC

S

The bachelor had chopped (a piece of) wood at the forest for the maiden.

(6) Avalent verbal

Lumilindol.

earthquake.IMPRF

$\mathrm{P}=\mathrm{AV}$

Earthquake is happening.

It can be noticed that the sentence patterns depend on the predicate, which in Tagalog naturally occurs at the beginning of the sentence. As a Philippine-type language, Tagalog has a compex verbal morphology, in which the affixation of the verbal affixes to the stem would determine the kind of complements the verb can take (Jubilado, 2004: 44). The predicates are characterised through the notion of valency, or the number of slots available for the arguments. The argument refers to the participant or complement that obligatorily occurs in a sentence.

Sentence (1) represents the type of Tagalog sentence that is called nonverbal, i.e., the predicate is not a member of the lexical category verb. The predicate natulog in (2) requires only the subject argument (ang binata); it is also called a 'one-place' predicate. Returning to (1), it can be seen that the predicate maganda also requires one complement, the subject (ang dalaga), in order for the sense of the sentence to be complete. Sentence (3) requires a subject (ang guro) and predicate-complement (sa Malabon) in order to complete the semantics of the verb pumunta, which also the predicate.

Sentences (4) and (5) are transitive constructions, which comprise the most prolific of the sentence patterns. One can notice that in Tagalog, the verb which is the verb of the sentence may require two or more predicate-complements. 
In Tagalog, the predicate-complement represents the complements that can be focused by the verb, according to the semantics of the predicate (Malicsi, 2012). Hence, any focusable complement in Tagalog may be assigned the grammatical subject of the sentence, which is done by assigning the nominal marker ang. Phrases, such as some prepositional phrases, which cannot be focused by the verbal predicate, function as adjuncts of the sentence (Malicsi, 2012: 52). In other languages such as English, the prepositional phrase is naturally spatial, which is why instead of the term prepositional phrase, the researcher shall use the term noun phrase complement in order to determine the predicate-complements of the sentence. Since the predicate-complements may be assigned as the grammatical subject, the sentences that have these types of complements are considered as belonging to the class of transitive sentences (Radden \& Driven, 2007).

\section{Participant roles and event schema}

The event schemas that will be discussed in this paper may be summarised in three "worlds of experience": material world, psychological world, and forcedynamic world. Material world refers to how the structured world exists, changes, or undergoes processes (Radden \& Dirven, 2007: 272). The psychological world is the internal world of human sensation, emotion, perception, and thought. The force-dynamic world is the external world of action, force, and cause-and-effect relations. Events within the material world differ from those within the forcedynamic world, in that within the latter world, the human is the primary instigator of the events. Through the three worlds of experiences mentioned, we can construct an inventory of the event schemas in Tagalog; however, in this study, only the events in the material world and the psychological world shall be discussed, analysis of Tagalog sentences that illustrate events in the force-dynamic world is reserved for further research.

\section{Situations in the material world}

Events that are included in the material world are comprised of events that describe state and process, location and motion, and possession (Radden \& Dirven, 2007: 272). These situations may be classified into three event schemas: occurrence schema, spatial schema, and pertinence/possession schema. These three event schemas are similar in that they harbour the role THEME.

\section{a. Occurrence scheme}

The occurrence schema describes a state or process that an entity undergoes. According to Radden and Dirven (2007: 272), the notion 'occurrence' pertains to the sense of condition or event involving objects in the material world. For this 
reason, the situations included in the occurrence schema are characterised as having a subject that has the role THEME. Under the occurrence schema are two subcategories: state, that expresses a simple atemporal relation, and process, that expresses a complex temporal relation.

The state is the relationship between the THEME and another entity that describes the former: "THEME is of non-verbal predicate property". Its simple atemporal relation is expressed through a non-verbal sentence construction that consists a subject and non-verbal predicate. The state has the following schema:

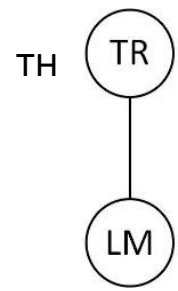

Figure 1. Schema for state.

Figure 1 illustrates that the TRAJECTOR is the THEME, because it is where the focus is in the sentence, and the predicate of the state schema is the LANDMARK, which is 'where the condition of the TRAJECTOR is happening'. Different types of non-verbal predicate give different meanings to the state. Notice the following set of sentences:

(7) Matamis ang baon=ko.

sweet lunch=my

$\mathrm{P} \quad \mathrm{S}$

My lunch is sweet.

(8) Prutas ang baon=ko.

fruits lunch=my

$\mathrm{P} \quad \mathrm{S}$

My lunch is fruits.

(9) Ang mangga ang baon=ko.

the mango lunch=my

$\mathrm{P} \quad \mathrm{S}$

My lunch is the mango. 
The THEME ang baon $k o$ in (7) is assigned the property matamis (property assignment). In (8), the THEME ang baon ko is included in the category 'fruits' (category inclusion). Meanwhile, the predicate in (9) is given a new and additional identity that is represented by the NP ang mangga (identification). Nominal sentences in Tagalog, i.e., sentences with NP for predicate such as in (8) and (9), are usually given two interpretations: NP-predicates that do not have a determiner have a classificatory sense (8), while those that have a determiner (ang) have an identificational sense (9).

The process pertains to state that either changes or remains unaltered. A change of signals a transition from a former towards a new condition, whereas a steady process describes events that do not change. The process schema includes change of state, that expresses a complex temporal relation, and steady process, that expresses a simple temporal relation.

Be it sudden or gradual, the change of state focuses on the new state. The beginning of a situation is called inchoation, and the verbs that express a beginning of an event are called inchoative verbs. Usually, the change-of-state verbs have an inchoative meaning, illustrated by the sentence (10) below:

$\begin{array}{lll}\text { Naging } & \text { maayos } & \text { ang buhay=niya } \\ \text { to become.PRF } & \text { better } & \text { life=his } \\ \mathrm{P} & & \mathrm{S}\end{array}$

His life had become better.

The change of state can be said to be related to the essential concept of state. However, instead of describing it as "THEME is of non-verbal predicate property", the change of state may include a relation that demonstrates change: "THEME becomes of non-verbal predicate property". In this case the change of state schema describes a complex temporal relation, as shown in Figure 2 below:

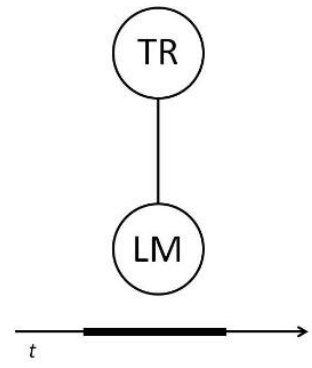

Figure 2. Schema for change of state. 
The THEME that undergoes change is the TRAJECTOR, which is given focus in the sentence. The change of state in Tagalog has an inchoative verb naging for predicate. Meanwhile, an equivalent meaning may also be expressed through the use of a verbalised adjective as a predicate:

Sumungit to become prickish.PRF

The teacher had become prickish.
Gumanda
to become beautiful.PRF
The smokey mountain had become beautiful.
ang smokey mountain.
the smokey mountain

ang titser.

the teacher

The above sentences can be seen as derived from naging masungit ang titser (for (11)) and naging maganda ang smokey mountain (for (12)). For that reason, this type of sentence is also included in the change-of-state type.

A steady process describes an action that involves a non-human or nonvolitional THEME. Notice the following examples:

$$
\begin{array}{ll}
\text { Sumisikat=na } & \text { ang araw. } \\
\text { to rise.PRF=already } & \text { the sun } \\
\mathrm{P} & \mathrm{S}
\end{array}
$$

The sun is already rising.

$$
\begin{array}{ll}
\text { Nagliwanag } & \text { ang buwan. } \\
\text { to shine.PRF } & \text { the moon } \\
\mathrm{P} & \mathrm{S}
\end{array}
$$

The moon had shone.

Steady processes are situations that remain unchanged; they may be represented by an intransitive sentence that requires only one participant, the THEME, as in (13) and (14). However, steady processes in Tagalog may also be represented by a transitive sentence, provided that the verb focuses its locative complement, as shown in the following sentence:

$\begin{array}{lll}\text { Sinikatan } & \text { ng araw } & \text { ang kapatagan } \\ \text { to shine down.PRF } & \text { the sun } & \text { the plain.FOC } \\ \mathrm{P} & \mathrm{CP} & \mathrm{S}\end{array}$

The plain was where the sun had shone down on. 
Although in a sense a steady process remains unchanged, the predicates may be inflected in any aspect ((13), (14), and (15)). Generally, the process schema as the following abstraction: "THEME[-HUMAN/-voltTIONAL] undergoes process (on LOCATION)". For this research only the non-human THEME will be focused, i.e., those that are related to nature. However, there are modal affixes in Tagalog that when connected to the verb, the latter would be interpreted as being done by a "not intentionally acting" human. Because of the semantics of the predicate of a steady process, the said schema describes a simple temporal relation, wherein the THEME is the TRAJECTOR or focal point of the sentence (cf. Figure 1).

Also included in this category is the phenomenological sentence, a sentence that describes natural conditions, such as climate, weather or season, and geological processes. In Tagalog, phenomenological sentences are represented by avalent verbal sentences, those that do not have an overt subject, like (16) at (17):

(16) Umuulan.

to rain.IMPRF

AV

It is raining.

(17) Maginaw.

cold

AV

It is cold.

It is said that the referent of the non-overt subject in this type of sentence is the overall natural condition; the THEME that describes the setting of the phenomenological condition of the situation is also called subject setting (Radden \& Dirven, 2007: 276).

A typical phenomenological sentence may undergo semantic change to become a change-of-state when the adverbial na is added to it ((18) and (19)):

(18) Tag-init=na.

dry season=already

AV

It is dry season already.

(19) Pasko=na.

Christmas season=already

AV

It is Christmas season already. 


\section{b. Spatial schema}

A spatial schema describes relations between the THEME and LOCATION or TRAJECTORY (Radden \& Dirven, 2007: 276). It can be classified into static or dynamic such as the occurrence schema. The static spatial schema is related to LOCATION: this type of relation is called location schema. As for the dynamic spatial schema, the moving theme is related to its TRAJECTORY: this type of relation is called motion schema.

A location schema expresses a simple atemporal relation: in Tagalog, the unconjugable verbal predicate ( $n a$ - and may) gives information about the relation between the LOCATIVE complement and the TRAJECTOR of the sentence (cf. Figure $1)$.

The location in Tagalog is expressed using sentences predicated by "nasa + $\mathrm{NP}^{\prime \prime}$. At this point, the morpheme na will be regarded as an unconjugable verb (cf. Malicsi (2012)) that profiles spatial/pertinent relation between the THEME (TRAJECTOR) and LANDMARK, which in turn indicates the location of the former: "THEME exists in LOCATION":

$\begin{array}{ll}\text { (20a) Na.sa mesa } & \text { ang ulam. } \\ \text { exist.on the table } & \text { the food } \\ \text { P.CP } & S\end{array}$

The food is (existing) on the table.

To regard na (and later on to its negative counterpart wala) in (20a) as a verb instead of preposition is based upon the paradigm that is set in this paper, that is, the prepositional phrase (that is headed, as the name suggests, by a preposition, or generally a nominal marker) may be focused by the predicate of the sentence (Malicsi, 2012). However, despite itself being a verb, $n a$ is perceived as of the unconjugable type. The verb $n a$ is unconjugable because it does not conform to the inflection paradigm of Tagalog verbs that determines the aspect and/or mode of the action. However, this unconjugable verb na has the durative sense: there is no certain beginning or end. This will also be the lens through which may will be discussed below, also according to Malicsi (2012).

The morpheme nasa is usually given the gloss 'in the' and is regarded as a preposition. However, looking at the different derivative sentences below, one can paradigmatically see that only the morpheme $s a$ is substituted by other morphemes:

$\begin{array}{ll}\text { Na.kay Damulag } & \text { ang ulam. } \\ \text { exist.with Damulag } & \text { the food } \\ \text { P.CP } & \text { S } \\ \text { The food is (existing) with Damulag. }\end{array}$


$(22 a)$

$\begin{array}{ll}\text { Na.kina Damulag at Dabiana } & \text { ang ulam. } \\ \text { exist.with Damulag and Dabiana } & \text { the food } \\ \text { P.CP } & S\end{array}$

The food is (existing) with Damulag and Dabiana.

$(23 a)$

$\begin{array}{ll}\text { Na.rito } & \text { ang ulam. } \\ \text { exist.here } & \text { the food } \\ \text { P.CP } & S\end{array}$

The food is (existing) here.

(24a) Na.riyan ang ulam.

exist.there the food

P.CP S

The food is (existing) there.

$(25 a)$

Na.roon ang ulam.
exist.there the food
P.CP S

It can be noticed that the forms that take the place of $s a$ are the nominal markers kay (21a) and kina (22a), and the demonstrative pronoun rito (23a), riyan (24a), and roon $(25 \mathrm{a})^{6}$

Analysing the negative counterparts of Sentences (20a) to (25a), one can see that only the morpheme $n a$ is changed, as in the following sentences below:

$(20 b)$

$\begin{array}{ll}\text { Wala.sa mesa } & \text { ang ulam. } \\ \text { negexist.on the table } & \text { the food } \\ \text { P.CP } & S\end{array}$

The food is not (existing) on the table.

(21b) Wala.kay Damulag ang ulam. negexist.with Damulag the food P.CP S

The food is not (existing) with Damulag. 
$(22 b)$

$\begin{array}{ll}\text { Wala.kina Damulag at Dabiana } & \text { ang ulam. } \\ \text { negexist.with Damulag and Dabiana } & \text { the food } \\ \text { P.CP } & \end{array}$

The food is not (existing) with Damulag and Dabiana.

(23b) Wala.rito ang ulam.

negexist.here the food

P.CP S

The food is not (existing) here.

(24b) Wala.riyan ang ulam.

negexist.there the food

P.CP $\quad S$

The food is not (existing) there.

$\begin{array}{ll}\text { (25b) Wala.roon } & \text { ang ulam. } \\ \text { negexist.there } & \text { the food } \\ \text { P.CP } & S\end{array}$

The food is not (existing) there.

For that reason, the form nasa can be said to actually consist no less than two morphemes: $n a$, as well as wala, which are regarded as unconjugable verbs that indicate LOCATION, and $s a$, which is a nominal markder that serves as the specifier of the LOCATIVE complement.

Consider the following sentences:

$\begin{array}{ll}\text { Na.sa entablado } & \text { ang dalaga. } \\ \text { exist.on the stage } & \text { the maiden } \\ \text { P.CP } & S\end{array}$

The maiden is (existing) on the stage.

\begin{tabular}{|c|c|c|}
\hline $\begin{array}{l}\text { Kumakanta } \\
\text { to sing.IMPRF }\end{array}$ & $\begin{array}{l}\text { sa entablado } \\
\text { on the stage }\end{array}$ & $\begin{array}{l}\text { ang dalaga. } \\
\text { the maiden.FOC }\end{array}$ \\
\hline $\mathrm{P}$ & Adjunct & $S$ \\
\hline
\end{tabular}

The difference between the two instances of sa entablado in the sentences above is clear in Tagalog. In (26), the phrase sa entablado is a complement of the unconjugable verb $n a$, which plays the role of a participant that completes the 
semantics of the predicate. Meanwhile, the same phrase that occurs in (27) serves as the spatial setting of the situatioon: it is an adverb of place - an adjunct - that if removed, will not cause the ungammaticality (ill-formedness) of the construction. This is not the case with (26) that if sa entablado is removed, the preposition loses its sense for it is supposed to express the relationship between the two NPs.

In (26) above, the THEME ang dalaga is a definite referent. In Tagalog, the definiteness of a noun phrase is encoded in the focus marker ang, which is why sentences with no definite grammatical subject in Tagalog do not exist (Reid \& Liao, 2004). As shown in (28) below, only the complement pera(-ng nahulog sa lupa) that serves as the subject of the unconjugable verb may is considered indefinite grammatical subject ${ }^{7}$ :

$$
\begin{aligned}
& \text { May pera=ng nahulog sa lupa. } \\
& \text { exist money=that fell on the ground } \\
& \text { There was money that fell on the ground. }
\end{aligned}
$$

This means that in the unverse of discourse, the identity of the entity being referred to is already known to both the speaker and the hearer of the utterance. A referrent is therefore considered definite when the mental space for the said referent is revealed; this is the subject of the sentence.

Each of sentences (20) to (29) discussed within the location schema has its own unconjugable verb, respectively, which requires one participant and one complement that determines the location of the participant. Hence, this type of sentence is considered of the intransitive-predicate-complement type.

However, there exists a sentence in Tagalog that is considered as a type of location schema but has no LOCATION participant. Consider the following sentence:

$$
\begin{aligned}
& \text { May tao sa banyo. } \\
& \text { exist person in the bathroom } \\
& \text { There's a person in the bathroom. }
\end{aligned}
$$

Constructions like (29) above are commonly called existential sentences: "a THEME exists". This type consists an unconjugable verb predicate may and is proceeded by a noun that is not assigned with a nominal marker. The loss of the nominal marker indicates that that noun is indefiniteness; in fact, this type of sentence is commonly used in introducing a new entity within a discourse. In the terminology of CG, the so-called existential sentence is a space-builder that reveals a mental space where the THEME, which is also the grammatical subject of the construction, exists (Radden \& Dirven, 2007: 277). If the location is not specified (that is usually 
expressed through NP-LOCATION as illustrated in (30) below), the THEME is understood to exist in universality, as illustrated in (31):

(30) May mga demonyo sa mundo.

exist demons in the world

There are demons in the world.

(31) May Dios.

exist God

There is a God.

The motion schema illustrates the change undergone by the THEME, particularly the trajectory, or path, that it travels - from one place and instant to another place instant (Radden \& Dirven, 2007: 278). The motion event is represented by (in) transitive-predicate-complement: it is directional and specifies the SOURCE, PATH, and/or GOAL. The motion schema describes a complex temporal relation that is represented by the following illustration:

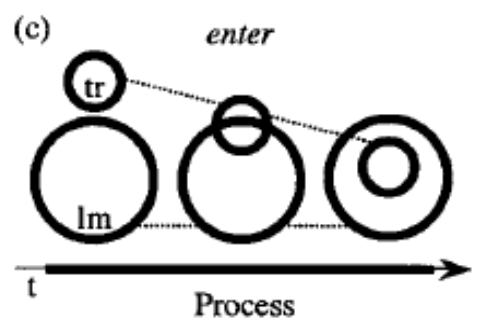

Figure 3. Representation of enter (Adapted from Langacker (2008: 117)).

Normally the tendency of a motion is for it to finish (verb telicity); that is, from a SOURCE, it travels through a PATH, and ultimately reaches its GOAL. Motion, whose abstraction is "THEME moves along TRAJECTORY" is the basis of the three basic event schemas: object motion and self-motion, and caused motion, which are represented by the following sentences:

$\begin{array}{lll}\text { Pumasok } & \text { ang bola } & \text { sa loob ng silid. } \\ \text { to enter.PRF } & \text { the ball.FOC } & \text { inside the room } \\ \mathrm{P} & \mathrm{S} & \text { CP }\end{array}$

The ball had entered the room. 


$\begin{array}{lll}\text { Pumasok } & \text { ang pusa } & \text { sa loob ng silid. } \\ \text { to enter.PRF } & \text { the cat.FOC } & \text { inside the room } \\ \text { P } & S & C_{P}\end{array}$

The cat had entered the room.

$\begin{array}{llll}\begin{array}{l}\text { Nagpasok } \\ \text { to bring.PRF }\end{array} & \begin{array}{l}\text { ng laruan } \\ \text { a toy }\end{array} & \begin{array}{l}\text { sa loob ng silid } \\ \text { inside the room }\end{array} & \begin{array}{l}\text { ang bata. } \\ \text { the } \\ \text { child. }\end{array} \\ \text { P } & \text { O } & \text { CP } & \text { FOC } \\ \text { S }\end{array}$

The child had brung a toy inside the room.

Sentence (32) demonstrates a non-agentive object motion, while self-motion (33) and caused motion (34) sentences are typically agentive. Self-motion and caused motion schemas will be discussed later on.

\section{c. Pertinence/possession schema}

The pertinence/possession schema, that is represented by a non-verbal sentence, consists a THEME, which is usually a physical object, and its relationship with another entity, usually a human. This schema describes a simple atemporal relation (Figure 1); but, the TRAJECTOR-LANDMARK alignment depends on which is the focal point of the sentence.

In Tagalog, a pertinence is usually interpreted as possession (Malicsi, 2012: 50), which has the following abstraction: "THEME exists in POSSESSOR", which is why pertinence and possession fall under a single category. The relationship between the abstraction of location schema and possession schema can be seen in the following sentences:

$$
\begin{array}{lll}
\text { May } & \text { ulam } & \text { ang kapitbahay. } \\
\text { exist } & \text { food } & \text { the neighbour.FOC } \\
\text { P } & \text { CP } & \text { S }
\end{array}
$$

The neighbour has some food.

(36) Isda ang ulam ng kapitbahay.

fish the food of the neighbour

$\mathrm{P} \quad \mathrm{S}$

The food of the neighbour is fish.

$$
\begin{aligned}
& \text { Na.sa kapitbahay ang ulam. } \\
& \text { exist.with the neighbour } \\
& \text { P.CP } \\
& \text { The food is (existing) with the neighbour. }
\end{aligned}
$$




$\begin{array}{ll}\text { Isda } & \text { ang kanyang=ulam. } \\ \text { fish } & \text { food=his } \\ \mathrm{P} & \mathrm{S}\end{array}$

His food is fish.

(39)

$\begin{array}{lll}\text { [Poetic] } & \text { Isda } & \text { ang sa kapitbahay na ulam. } \\ \text { fish } & \text { the neighbour's food } \\ \mathrm{P} & \mathrm{S}\end{array}$

The neighbour's food is fish.

Sentence (35) above has a number of differences with an existential construction discussed under location schema. The definite subject ang kapitbahay has the role POSSESSOR of the NP that is indicated by the may-phrase (may ulam). It differs from the existential construction in which the subject - which is indefinite - is incorporated to the may-phrase, and may have a prepositional phrase (functioning as an adjunct that describes a specific location of action) or may not (describes a universal existence), like the sentence May ulam sa kapitbahay. Meanwhile, (36) is a nominal sentence that possesses a subject that contains a pertinence phrase, the construction is interpreted as an instance of possession, i.e., an NP that has a $n g$ phrase (ng kapitbahay) that functions as POSSESSOR of the head of the NP-subject, ang ulam. The relation between the possession and location in Tagalog can be seen if (35), (37), and (38) are analysed. If the complement of may in (35), ulam, becomes the subject, the NP-POSSESSOR becomes of the sa-form, sa kapitbahay, which is the complement of the unconjugable verb na (37). As for (36), if the $n g$-phrase $n g$ kapitbahay, which is the POSSESSOR of the head of the subject NP ang ulam, is preposed, or put at the beginning of the head, the marker becomes $s a$, although the resultant form of the sentence is considered poetic or has literary licence (39). This type of construction is more commonly heard with personal pronouns that function as POSSESSOR and of the sa-form type, as shown in (38).

\section{Situations in the psychological world}

Situations in the psychological world describe human experiences, such as emotion, perception, and thought. Schemas - like emotion schema and cognition schema - both express complex temporal relations (Figure 2), in which the EXPERIENCER is the TRAJECTOR, and the LANDMARK is the state that the EXPERIENCER underwent, or the STIMULUS or OBJECT of EXPERIENCER (for the emotion schema) or the PERCEPT (for the cognition schema). 


\section{a. Emotion schema}

The emotion schema illustrates the condition or the emotional process consciously experienced by a human. Among the three psychological schemas mentioned, only the emotion schema may have only the EXPERIENCER as the sole argument, as in the following intransitive sentence:

$\begin{array}{ll}\text { Nalungkot } & \text { ang kuya. } \\ \text { to become sad.PRF } & \text { the brother } \\ \mathrm{P} & \mathrm{S}\end{array}$

The brother had become sad.

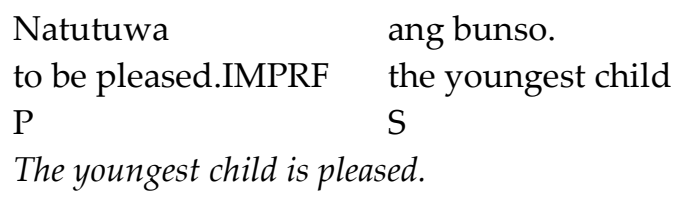

However, there is undeniably an implicit reason for experiencing an emotional state. In Tagalog, if the emotional schema contains a ma-form verb (as in nalungkot in (40) and natutuwa in (41)), the resultant sentence is intransitive, in which the grammatical subjects ang kuya (in (40)) and ang bunso (in (41)) play the role EXPERIENCER.

The emotional schema in Tagalog is not only expressed by an intransitive sentence like in (40) and (41). There are verbs that function as predicate of transitive sentence, illustrated by the following:

$\begin{array}{lll}\text { Tinakot } & \text { ng mama } & \text { ang bata. } \\ \text { to scare.PRF } & \text { the man } & \text { the child.FOC } \\ \mathrm{P} & \mathrm{CP}_{P} & \mathrm{~S}\end{array}$

The child had been scared off by the man.

$\begin{array}{lll}\text { Ginagalit } & \text { ng bata } & \text { ang nanay. } \\ \text { to anger.IMPRF } & \text { the child } & \text { the mother.FOC } \\ \mathrm{P} & \mathrm{CP} & \mathrm{S}\end{array}$

The mother had been angered by the child.

$\begin{array}{lll}\text { Nanakot } & \text { ng bata } & \text { ang mama. } \\ \text { to scare.PRF } & \text { the child } & \text { the man.FOC } \\ \mathrm{P} & \mathrm{CP} & \mathrm{S}\end{array}$

The man had given a scare to a child. 


$\begin{array}{lll}\text { Nanggagalit } & \text { ng nanay } & \text { ang bata. } \\ \text { to anger.IMPRF } & \text { the mother } & \text { the child.FOC } \\ \mathrm{P} & \mathrm{CP}_{\mathrm{P}} & \mathrm{S}\end{array}$

The child had been making his mother angry.

Sentences (42) through (45) show that there are Tagalog verbs that may require more than one complement. In (42) and (43), the focus is on the EXPERIENCER, the one that experiences the emotion verb takot (ang bata) and galit (ang nanay). On the other hand, the grammatical subject of (44), ang mama, and (45), ang bata, is the AGENT, or instigator of the predicates takot and galit. The maN- affix is used to focus the AGENT; the construction would be ungrammatical had the typical AGENTfocusing affix -um- or mag- (*tumakot; ${ }^{*}$ gumalit). The interpretation of the EXPERIENCER becomes classificatory or indefinite in this sentence configuration.

Consider the following sentences:

$\begin{array}{lll}\begin{array}{l}\text { Natakot } \\ \text { to be frightened.PRF }\end{array} & \text { sa paputok } & \text { ang aso. } \\ \text { the firecrackers } & \text { the dog.FOC } \\ \mathrm{P} \quad \mathrm{CP} & \mathrm{S} & \\ \text { The dog had been frightened by the firecrackers. }\end{array}$

$\begin{array}{lll}\text { Nagalit } & \text { sa presidente } & \text { ang samahan. } \\ \text { to feel anger.PRF } & \text { the president } & \text { the group.FOC } \\ \mathrm{P} & \mathrm{CP}_{\mathrm{P}} & \mathrm{S}\end{array}$

The group had felt anger towards the president.

Instransitive predicate-complement sentences like the ones mentioned above have a STIMULUS as one of the complements. The STIMULUS is assigned the nominal marker $s a$ if it does not function as the grammatical subject. In (46a) and (47a), the EXPERIENCERs ang aso and ang samahan, are the ones being focused by their respective predicates. The role assigned to paputok and presidente is STIMULUS and not AGENT because of the different verbal affix if they are focused, as in (46b) and (47b) below:

$\begin{array}{llll}\text { (46b) Kinatakutan } & \text { ng aso } & \text { ang paputok. } \\ \text { to frighten.PRF } & \text { the dog } & \text { the firecrackers.FOC } \\ \text { P } & \text { CP } & \text { S }\end{array}$

The firecrackers had given the dog a fright. 
(47b) Kinagalitan to feel anger.PRF $\mathrm{P} \quad \mathrm{C}_{\mathrm{P}}$ ng samahan

the group $\mathrm{S}$ ang presidente.

the president.FOC

The president had angered the group.

The schema can therefore be summarised using the following formula:

"EXPERIENCER experiences emotion (towards STIMULUS)".

\section{b. Perception/cognition schema}

Perception/cognition schema describes the perceptual or mental consciousness of the EXPERIENCER towards an object. It has the following abstraction "EXPERIENCER perceives PERCEPT". One can see the closeness of perception and cognition through the verbs such as nakita/naliwanagan and narinig/naunawaan, as shown in the following transitive-predicate-complement sentences:

\begin{tabular}{|c|c|c|}
\hline (48a) & $\begin{array}{l}\text { Tiningnan } \\
\text { to look.PRF } \\
\mathrm{P}\end{array}$ & $\begin{array}{l}\text { ng pari } \\
\text { the priest } \\
\text { CP }\end{array}$ \\
\hline
\end{tabular}

The sky was looked up to by the priest.

$\begin{array}{lll}\text { Kinikilala } & \text { ng pulis } & \text { ang batas. } \\ \text { to respect.IMPRF } & \text { the policeman } & \text { the law.FOC } \\ \mathrm{P} & \mathrm{CP}_{\mathrm{P}} & \mathrm{S}\end{array}$

The law is respected by the policeman.

$\begin{array}{lll}\text { (50a) Susubaybayan } & \text { ng bayan } & \text { ang halalan. } \\ \text { to monitor.CONT } & \text { the nation } & \text { the elections.FOC } \\ \mathrm{P} & \mathrm{CP}_{\mathrm{P}} & \mathrm{S}\end{array}$

The elections will be monitored by the nation.

Like in the emotion schema, the PERCEPT of perception/cognition schema projects a different syntactic behaviour: the nominal marker $s a$ is assigned to it if it is not focused.

(48b) $\begin{array}{lll}\text { Tumingin } & \text { sa langit } & \text { ang pari. } \\ \text { to look.PRF } & \text { the sky } & \text { the priest.FOC } \\ \mathrm{P} & \mathrm{CP}_{\mathrm{P}} & \mathrm{S}\end{array}$
$\begin{aligned} & \text { The priest looked up to the sky. } \\ & \end{aligned}$


$(49 b)$

$\begin{array}{ll}\text { Kumikilala } & \text { sa batas } \\ \text { to respect.IMPRF } & \text { the law } \\ \mathrm{P} & \mathrm{CP}\end{array}$

The policeman respects the law.

(50b)

$\begin{array}{lll}\text { Susubaybay } & \text { sa halalan } & \text { ang bayan. } \\ \text { to monitor.CONT } & \text { the elections } & \text { the nation.FOC } \\ \mathrm{P} & \mathrm{CP}_{\mathrm{P}} & \mathrm{S}\end{array}$

The nation will monitor the elections. ang pulis.

the policeman.FOC

S

Based on the sentences above, the verbs follow the -um- paradigm: the focused complement is the EXPERIENCER (ang pari in (48b), ang pulis in (49b), and ang bayan in (50b)). Hence, the complements having the participant role PERCEPT are assigned the nominal marker $s a$ as in sa langit (48b), sa batas (49b), and sa halalan (50b).

In Tagalog, there are verbs that are limited in the number of complement(s) that can be focused, particularly those having the participant role PERCEPT. Consider the following sentences:

$\begin{array}{lll}\text { Nakita=ko } & \text { ang sagot } & \text { sa katabi=ko. } \\ \text { to see.PRF=I } & \text { the answer.FOC } & \text { the seatmate=my } \\ \mathrm{P}=\mathrm{CP} & \mathrm{S} & \mathrm{CP}_{\mathrm{P}}\end{array}$

The answer had been seen (by me) in my seatmate.

$\begin{array}{lll}\text { Nakita=ko } & \text { ang sagot } & \text { sa hilatsa ng mukha mo. } \\ \text { to see.PRF=I } & \text { the answer.FOC } & \text { in your face } \\ \mathrm{P}=\mathrm{CP} & \mathrm{S} & \mathrm{CP}_{\mathrm{P}}\end{array}$

The anwer had been seen (by me) in your face.

In (51) and (52), the NP ko with the participant role EXPERIENCER cannot be focused by a typical AGENT-focus verb (that which contains the infix -um- or the prefix mag); the construction would become ungrammatical (*kumita or ${ }^{*}$ magkita).

\section{Conclusion: Entrenchment of event schemas as images}

The categories of the simple sentences in Tagalog based on the CG echoes the principle that grammar and semantics cannot be separated; rather, the lexicon and grammar create a continuum of symbolic elements (Langacker, 2006: 41). 
Language is imagic: both the creation and symbolisation of conceptual contents are supplied by the lexicon and grammar. Hence, in the utterance of a linguistic unit from a morpheme thru a sentence, the speaker chooses a particular image schema in order to convey the observed situation to another speaker (Langacker, 2006: 41). The image schema is patterns of perceptual interaction, bodily action, and manipulation of object (Johnson, 1987; 1993; Lakoff, 1987, 1990; Talmy, 1988) that serve as dynamic analog representations of spatial relation and movement in space derived from perceptual and motor processes (Gibbs \& Colston, 2006: 239). Furthermore, based on the discussions above, the creation of a sentence is the use of entrenched schematic constructions resulting from the exposure to expressions of a particular language. This means that in an expression, the speaker forms the concept they want to convey first and afterwards finds the equivalent form from the entrenched constructions that will function as the sentence pattern. Hence, there is the necessity for the theoretical framework proposed by CG to demonstrate the mechanism in the entrenchment and retrieval of schematic assemblies, and not only in the assignment of meaning of different expressions of clause structures. Implicatively, CG responds to the need of having explicit descriptions of grammatical constructions of a language, and promoting how they are seen as imagic.

Because of the different perspective offered by CG, this paper aims to provide new insights as regards the characteristics of the components of grammar as a reflection of cognition, particularly of the Tagalog speaker. It seeks to contribute to the ever-growing knowledge not only of Tagalog, but of the general linguistic theory, by opening new avenues for future studies on Tagalog, and other Philippine languages, using CG, by creating an alternative methodology in the discipline of linguistics.

\section{References}

Enriquez, M. A. T. (2004). Isang analisis sa mga pangungusap na ELPP [An analysis of ELPP sentences]. Daluyan: Journal ng Wikang Filipino, 12(1), 616.

Evans, V. (2007). A glossary of Cognitive Linguistics. Salt Lake City: The University of Utah Press.

Evans, V., \& Green, M. (2006). Cognitive Linguistics: An introduction. Edinburgh: Edinburgh University Press Ltd.

Gibbs, R.W., Jr., \& Colston, H.L. (2006). The cognitive psychological reality of image schemas and their transformations. In D. Geeraerts, (Ed.), Cognitive Linguistics: Basic readings. Berlin: Mouton de Gruyter.

Harris, R.A. (1993). The Linguistics Wars. Oxford: Oxford University Press.

Johnson, M. (1987). The body in the mind. Chicago: University of Chicago Press. 
Johnson, M. (1993). Moral imagination. Chicago: University of Chicago Press.

Jubilado, R.C. (2004). Philippine linguistics, Filipino language, and the Filipino nation. JATI, 9, 43-54.

Jubilado, R.C. (2008). The Filipino language in the Malaysian linguistic space. JATI, 13, 147-158.

Lakoff, G. (1987). Women, fire, and dangerous things: What categories reveal about the mind. Chicago: University of Chicago Press.

Lakoff, G. (1990). The invariance hypothesis: Is abstract reason based on imageschemas? Cognitive Linguistics, 1(1), 39-74.

Langacker, R.W. (1987). Foundations of CG volume 1: Theoretical prerequisites. Stanford: Stanford University Press.

Langacker, R.W. (1991). Foundations of CG volume 2: Descriptive application. Stanford: Stanford University Press.

Langacker, R.W. (1994). Structural syntax: The view from CG. Semiotiques, 6-7, 6984.

Langacker, R. W. (2000). A dynamic usage-based model. In M. Barlow at S. Kemmer, (Eds.), Usage-based models of language. Stanford: CSLI Publications.

Langacker, R. W. (2002). Concept, image, symbol: The cognitive basis of grammar, $2^{\text {nd }}$ ed. Berlin: Mouton de Gruyter.

Langacker, R.W. (2006). CG: Introduction to concept, image, and symbol. In D. Geeraerts, (Ed.), Cognitive Linguistics: Basic readings. Berlin: Mouton de Gruyter.

Langacker, R. W. (2008). CG: A basic introduction. New York: Oxford University Press.

Malicsi, J.C. (2012). Pang-ukol sa Filipino [Prepositions in Filipino]. Daluyan: Journal ng Wikang Filipino, 18(1-2), 39-82.

Malicsi, J.C. (2014). Gramar ng Filipino. Quezon City: UP Diliman Sentro ng Wikang Filipino.

Quetua, F.L., et al. (1999). Sangguniang gramatika ng Wikang Filipino. Quezon City: UP Sentro ng Wikang Filipino Diliman.

Radden, G., \& Dirven, R. (2007). Cognitive English grammar. Amsterdam: John Benjamins Publishing Company.

Reid, L.A., \& Liao, H. (2004). A brief syntactic typology of Philippine languages. Language and linguistics, 5(2), 433-490.

Talmy, L. (1988). Force dynamics in language and cognition. Cognitive Science, 12, 49-100.

Talmy, L. (2005). [Foreword]. In M. Gonzalez-Marquez, I. Mittelberg, S. Coulson, and M. Spivey (Eds.), Methods in Cognitive Linguistics. Amsterdam: John Benjamins. 


\footnotetext{
${ }^{1}$ Much literature has been written regarding introspection as a linguistic methodology. L. Talmy, one of the leading scholars of CG, defines it as "...[a] conscious attention directed by a language user to particular aspects of language as manifest in her own cognition" (2005).

${ }^{2}$ The author wishes to reiterate that studying language or aspects of it through the lens of Cognitive Grammar is relatively new; for the reader who wishes to gain more understanding as regards the key concepts and terminology used in the framework will please refer to Evans's 2007 Glossary of Cognitive Linguistics, which provides useful operative definitions of those key concepts used in Cognitive Grammar. Meanwhile, terms in boldface type are given definitions to guide the reader of this paper.

${ }^{3}$ For a more in-depth discussion on the difference of CG to the other existing linguistic theories, see Harris (1993) and Evans and Green (2006: §22-23).

${ }^{4}$ In the case of the ditransitive sentence pattern, this paper shall not subscribe to that in relation to Tagalog; this study shall look into the multivalence of Tagalog - whichever complement that occurs in the sentence may be focused depending on the semantics of the predicate.

${ }^{5}$ Different from the obligatoriness of occurrence of a complement within a sentence, the term 'obligatory' has the sense of the possibility of becoming an argument and/or the grammatical subject of the sentence.

${ }^{6}$ The $n a-+$ demonstrative pronoun constructions have the allomorph nan- that is attached to the variant form of the demonstrative pronoun with [d] for the initial sound: narito nandito; nariyan $\sim$ nandiyan; and naroon $\sim$ nandoon.

${ }^{7}$ This is what is known as the topicless sentence as per Enriquez (2004) and Quetua, et al. (1999).
} 